\title{
Knowledge Management under the Background of Enterprise Bankruptcy
}

\author{
Yu Dingming, \\ Law School of Yunnan University of Finance and Economics, \\ Kunming, China \\ macunxiucai@126.com
}

\begin{abstract}
Knowledge management, as one of the main activities of enterprise management, can create value for an enterprise and so should be performed throughout the whole operation cycle of an enterprise. However, it is easily overlooked when an enterprise enters into the bankruptcy stage, which consequently causes losses for the enterprise in invisible property. Enterprise bankruptcy administrator or the manager responsible for bankruptcy reorganization shall carry out necessary enterprise knowledge management activities at the stage of liquidation or restructuring. Since current manager system is unfavorable for the knowledge management during bankruptcy stage, manager selection system shall be improved.
\end{abstract}

Keywords - enterprise; knowledge management; bankruptcy

\section{INTRODUCTION}

Since entering into the era of knowledge-based economy, the enterprises' close attention to "knowledge" has made "enterprise knowledge management" become an increasingly important matter in enterprise management activities. Researches repeatedly show that highly-efficient knowledge management activities have generated positive effect on business operations and that both the academic field and practical field realize and recognize the value of knowledge management for the enterprises. Enterprise knowledge management, especially the management of tacit knowledge is such a kind of activity that should run through the whole operation cycle of an enterprise. When an enterprise goes into bankruptcy, knowledge management which is resource and cost-consuming is put aside, forming a dead zone of enterprise knowledge management activities. But in fact, when an enterprise intends to restore solvency via bankruptcy reorganization, more normative knowledge management activities are desired to avoid the loss of the enterprise's tacit knowledge and other intangible assets. This paper aims to discuss the knowledge management at the bankruptcy reorganization stage of an enterprise on the basis of summarizing enterprise knowledge management procedure and objectives and in accordance with enterprise bankruptcy reorganization.

\section{IMPLICATION AND FEATURES OF ENTERPRISE}

\section{KNOWLEDGE MANAGEMENT}

Knowledge management (KM) has been a hot topic of the academic field and practical field since the 1990s. Nevertheless, neither the practical field nor the academic field has so far agreed on the definition of "enterprise knowledge management". According to the summary by scholars like Zuo Meiyun, the scholars conducting the definition research of enterprise knowledge management can be divided into such three schools as the behavior school, technology school and integrated school. The behavior school holds that "knowledge management is the management of people"; the technology school thinks that "knowledge management is the management of information"; while the integrated school claims that "knowledge management is not only the management of both information and people, but also the centralized management of information and people, namely, knowledge management needs to combine the information processing capability and the people's innovation capability so as to strengthen the adaptability of an organization to the environment". [1] Actually, in defining "enterprise knowledge management", it is necessary to firstly clarify what is "enterprise knowledge". The connotation of this 
concept is also hard to define, but the academic field has basically agreed on the scope of "enterprise knowledge": enterprise knowledge consists of explicit and tacit knowledge and the latter serves as the core of enterprise knowledge. [2]

Explicit knowledge refers to a kind of knowledge which can be or can be easily or has been expressed in a coded way, while tacit knowledge refers to a kind of knowledge which cannot be or cannot be easily or has not been expressed in coded way. [3] An enterprise's management of explicit knowledge is actually the management of effable and recordable information, essentially, the management of information. It can be realized by establishing information system, and the management procedure can be fixed and the management results are visible and measurable. An enterprise's management of tacit knowledge is actually the management of knowledge that has not been expressed in coded way. It cannot be fixed or quantified via information system, and only the management of the knowledge carriers' behavior, namely, the management of people, is achievable. Where the enterprise knowledge includes both the explicit and tacit knowledge, the management of the enterprise knowledge will certainly include the management of technology and people, which fits the definition of the integrated school: enterprise knowledge management is the management of both people and information and the management of interactive relationship between people and information. Enterprise knowledge management is actually a process in which various kinds of information is collected, coded, accumulated and saved, shared and exchanged to finally realize the innovation and value-adding of an enterprise. [4] The characteristics of these management activities in business operations are as follows:

\section{A. Enterprise knowledge management creating value for} an enterprise

Enterprise knowledge management can, by way of the regulation and control of knowledge and its carriers, realize the effects of reduced cost, improved efficiency, added value and new value creation. [5] In the knowledge flow, an enterprise can explore inherent knowledge, guide knowledge innovation, and realize knowledge sharing so as to finally enhance its competitiveness and realize sustainable development. If an enterprise applies the knowledge in products and services with exchangeable value and achieves profits by selling products or providing service, this knowledge management process creates value for the enterprise. Therefore, enterprise knowledge management is a kind of management activity that can create value for the enterprises.

\section{B. Enterprise knowledge management, a cost-consuming} management activity

Although the enterprise knowledge management activity can create value for the enterprises, it is an indirect process. The most direct manifestation is that enterprise knowledge management is a kind of management activity that consumes enterprise operating cost. For the management of explicit knowledge, material resources should be input and information system should be established for large-scale knowledge management; for the management of tacit knowledge, labor cost should be input and separate labor remuneration must be provided or management and control should be enhanced so as to realize effective management and control of the knowledge carriers. It is thus clear that the collection, coding, accumulation and saving, or sharing and exchange of knowledge incurs operating cost. Therefore, knowledge management is a kind of cost-consuming management activity.

\section{Relation to the whole operation cycle of an enterprise}

Even if the enterprise manager neither realizes that he/she is conducting knowledge management activity nor deliberately establishes knowledge management information system, it is actually a specific activity of enterprise knowledge management as long as the enterprise has planned and arranged the knowledge and its carriers generated in the course of production and operation. Although the enterprises' conscious practice of knowledge management is still in its infancy, and research on enterprise knowledge management is still immature, it cannot be denied that these management activities related to knowledge and its carriers are the specific contents of 
enterprise knowledge management. However, the regulation and management activities related to knowledge or its carriers often occur in the period from the enterprise's incorporation to termination, namely, the whole operation cycle of an enterprise.

Although the enterprise knowledge management activities shall run through the whole operation cycle, they are often put aside when the enterprise faces a survival crisis. Reducing the management activities which cannot directly generate profits is common practice among bankrupt enterprises. However, interruption of knowledge management activities can cause the disclosure of enterprise's knowledge, especially the disclosure of tacit knowledge to outsiders, e.g., loss of workers with special skills. This in fact cuts the opportunity for the enterprise to restore its solvency via bankruptcy reorganization and this dead zone in enterprise knowledge management process may hinder the realization of enterprise knowledge management objectives.

\section{KNOWLEDGE MANAGEMENT IN ENTERPRISE BANKRUPTCY PROCEDURE}

Enterprise bankruptcy, as a legal system which regulates the exit of main market players from the market and one of the necessary systems guaranteeing the orderly running of market economy, can shut out the "bad money" and promote the establishment of social credit, commercial credit, and personal credit. [6] When accepting and hearing a case of bankruptcy petition, the court will appoint one bankruptcy administrator. The said bankruptcy administrator shall be the liquidation team, or such intermediary agencies as law firm, accounting firm, and bankruptcy liquidation firm which are incorporated according to law. Its main responsibilities include the taking-over of the bankrupt enterprise, custody and liquidation of bankrupt properties, acting on behalf of the bankrupt enterprise in civil activities, disposal of bankrupt properties and the like.

When the administrator is appointed, the internal affairs and daily, necessary expenditures of the bankrupt enterprise shall be determined by the said administrator. As the administrator of enterprise is from external agency, it is hard for the administrator to comprehensively master the internal knowledge system of the bankrupt enterprise in a short period. Therefore, the judgment of the administrator on enterprise intangible knowledge information is not as sensitive as that on tangible assets (especially when the knowledge information originates from the special experience of the enterprise), since this kind of enterprise knowledge information is not universal and is hard to be identified by the administrator. The difficulty of the administrator in recognizing enterprise knowledge information will consequently lead to the administrator's unawareness of the tacit knowledge of the bankrupt enterprise or his/her refusal to recognize the value of the explicit knowledge. At the same time, the terms of reference of the administrator is in fact very large. According to the Enterprise Bankruptcy Law, the administrator can dispose of the intellectual property of a bankrupt enterprise as long as he/she timely reports to the Creditors' Committee or People's Court. As a result, the administrator is prone to make improper judgment and disposal concerning the enterprise knowledge management, which will undoubtedly cause wealth loss for the bankrupt enterprise.

In practice, the entry of an enterprise into the bankruptcy procedure does not mean inevitable termination of the enterprise. "Bankruptcy reorganization" in bankruptcy system provides the enterprise with an opportunity to improve operation and restore solvency. Bankruptcy reorganization refers to a legal system by which business restructuring and liquidation of claim are forcibly carried out in the enterprise that is likely to go or went bankrupt, but with the hope of being saved via interest coordination between all interested parties to avoid the said enterprise going bankrupt. [7] After the application of an enterprise for the entry into the bankruptcy reorganization period is approved by the court, the bankrupt enterprise itself can manage its properties and business affairs under the supervision of the administrator. When the bankrupt enterprise manages its properties and business affairs independently, the protection of the enterprise's knowledge 
information will certainly be more thorough than if done by the administrator. Nevertheless, the bankrupt enterprise must carry out business activities as per the reorganization plan passed at the meeting of creditors and approved by the court and accept the supervision by the administrator in the supervision period as specified in the reorganization plan. This means that the operation of the bankrupt enterprise in the reorganization period must also be carried put as per the value judgment of the administrator. When the administrator refuses to recognize the value or scope of the enterprise knowledge information, the bankrupt enterprise will have difficulty in performing necessary knowledge management. For example, continuously-highlighted work like the collection and saving, sharing and exchange in the production process of knowledge information with other enterprises and the provision of knowledge and skill training for the staff cannot create direct benefits immediately but will consume administration cost. Although it is of significance to enterprise development, it will still be denied by the bankruptcy administrator.

It is thus clear that there are many obstacles preventing the performance of knowledge management activities which should be carried out through the whole operation cycle of an enterprise.

\section{Manager Qualifications With Perspective on}

\section{ENTERPRISE KNOWLEDGE MANAGEMENT}

It can be seen from the above discussion that although the administrators still attach great importance to the enterprise knowledge management, his/her management of bankrupt enterprise's knowledge, especially the tacit knowledge, is at a distinct disadvantage compared to that by the original operator. Therefore, it is necessary to modify the qualifications of the bankruptcy administrator from the perspective of enterprise knowledge management.

Current Enterprise Bankruptcy Law stipulates that such intermediary agencies as liquidation team, law firm, accounting firm, bankruptcy liquidation firm and their employees who are armed with relevant expertise and qualification certificates can act as the administrator. This regulation highlights that the administrator shall have legal and financial knowledge. Obviously, this regulation, specially designed in terms of enterprise bankruptcy liquidation proceedings, does not take the administrators of enterprise bankruptcy reorganization and reconciliation process into consideration. In fact, the more important ability that the administrator needs to have is the operation and management ability to make the enterprise survive in the bankruptcy reorganization or reconciliation process rather than just the legal and financial knowledge. With the approval of the people's court, the administrator may employ necessary personnel. In this way, the administrator's lack of operation and management ability may likely be compensated in general. However, this leads to "putting the cart before the horse" and the people's court is not good at the operation and management of enterprises. Therefore, the Enterprise Bankruptcy Law shall distinctively stipulate that the administrator may be determined as per existing regulations when an enterprise goes into the bankruptcy liquidation proceedings, while the professional manager should act as the administrator if the enterprise enters into reorganization or reconciliation process. Namely, the Enterprise Bankruptcy Law shall otherwise so stipulate the administrator qualifications regarding bankruptcy reorganization and reconciliation process that the operation and management ability is the essential condition. The professional manager may, without the prior approval of the people's court, invite a lawyer and certified public accountant to participate in the management of the bankrupt enterprise where he/she thinks it is necessary.

\section{CONCLUSION}

In summary, the enterprise knowledge management is a type of management activity that can create value for the enterprises and therefore shall be performed through the whole operation cycle of the enterprises even if it will consume certain amount of operating cost. The enterprises shall carry out necessary knowledge management activities even if they are at the stage of bankruptcy and shall avoid improper disposal of knowledge information. Enterprise knowledge, as a kind of wealth, is different from tangible 
wealth. Even for explicit knowledge, its value is not certainly reflected directly in the balance sheet or income statement of the enterprise. The value of tacit knowledge, which is much more significant to the enterprise, is much harder to measure. Risk of improper knowledge management may even occur in normal operation, so it is hard to insist on knowledge management when an enterprise goes bankrupt. Lack of necessary knowledge management may cause loss of recessive properties in most cases. At the bankruptcy stage, the manager enjoying absolute discretion in enterprise operation shall realize this problem and organize necessary knowledge management activities.

\section{REFERENCES}

[1] Zuo Meiyun, Xu Ke, and Chen Yu. Study on the Content Framework of Enterprise Knowledge Management, [J] Journal of Renmin University of China, 2003(5), p70-71.

[2] Chu Jiewang, Zhou Shaosen. Introduction of Knowledge Management, [M] , Tsinghua University Press and Beijing Jiaotong University Press (2006), p32.

[3] Zhou Chengxiong. Concept Discrimination of Tacit Knowledge \& Explicit Knowledge, [J] Information studies: Theory \& Application, 2004 (2), p128.

[4] Jiang Yun'er: Study on the Basic Elements of Corporate Knowledge Management,[D], Hohai University, (2002), P46-47

[5] Yu Shanshan: Knowledge Management: Create Max. Value for Enterprises, [J] ,Information Research, 2005(5), p88

[6] Li Shuguang: Significance, Breakthrough and Influences of New Enterprise Bankruptcy Law, [J],Journal of the East China University of Political Science and Law, 2006 (6), p111

[7] Wang Xinxin: Bankruptcy Law (Version 2), [M] ,China

Renmin University Press (2007), p342-344 